\title{
Trait-based responses to land use and canopy dynamics modify long-term diversity changes in forest understories
}

\author{
Konsta Happonen ${ }^{1}$ (D) | Lauralotta Muurinen ${ }^{2}$ | Risto Virtanen ${ }^{2}$ | Eero Kaakinen ${ }^{2}$ | \\ John-Arvid Grytnes $^{3}$ | Elina Kaarlejärvi ${ }^{4}$ (D) | Philippe Parisot ${ }^{5}$ | Matias Wolff ${ }^{2}$ | \\ Tuija Maliniemi ${ }^{3,5}$
}

\author{
${ }^{1}$ Department of Geosciences and \\ Geography, University of Helsinki, Helsinki, \\ Finland \\ ${ }^{2}$ Ecology and Genetics Research Unit, \\ University of Oulu, Oulu, Finland \\ ${ }^{3}$ Department of Biological Sciences, \\ University of Bergen, Bergen, Norway \\ ${ }^{4}$ Research Center for Ecological Change, \\ Organismal and Evolutionary Biology \\ Research Programme, University of Helsinki, \\ Helsinki, Finland \\ ${ }^{5}$ Geography Research Unit, University of \\ Oulu, Oulu, Finland

\section{Correspondence and Environmental Sciences, University of Gothenburg, Gothenburg, Sweden. \\ Email: konsta.happonen@gmail.com} \\ Konsta Happonen, Department of Biological
}

\section{Present address}

Konsta Happonen, Department of Biological and Environmental Sciences, University of

Gothenburg, Gothenburg, Sweden

\section{Funding information}

The Finnish Society of Forest Science; Societas Biologica Fennica Vanamo; Jane $\&$ Aatos Erkko Foundation; Academy of Finland, Grant/Award Number: 259072; Suomen Kulttuurirahasto; Societas Pro Fauna et Flora Fennica; Societas Amicorum Naturae Ouluensis

Editor: Benjamin Blonder

\begin{abstract}
Aim: Land use is the foremost cause of global biodiversity decline, but species do not respond equally to land-use practices. Instead, it is suggested that responses vary with species traits, but long-term data on the trait-mediated effects of land use on communities are scarce. Here we study how forest understorey communities have been affected by two land-use practices during 4-5 decades, and whether changes in plant diversity are related to changes in functional composition.

Location: Finland.

Time period: 1968-2019.

Major taxa studied: Vascular plants.

Methods: We resurveyed 245 vegetation plots in boreal herb-rich forest understories, and used hierarchical Bayesian linear models to relate changes in diversity, species composition, average plant size, and leaf economic traits to reindeer abundance, forest management intensity, and changes in climate, canopy cover and composition. We also studied the relationship between species evenness and plant size across both space and time.

Results: Intensively managed forests decreased in species richness and had increased turnover, but management did not affect functional composition. Increased reindeer densities corresponded with increased leaf dry matter content, evenness and diversity, and decreased height and specific leaf area. Successional development in the canopy was associated with increased specific leaf area and decreased leaf dry matter content and height in the understorey over the study period. Effects of reindeer abundance and canopy density on diversity were partially mediated by vegetation height, which had a negative relationship with evenness across both space and time. Observed changes in climate had no discernible effect on any variable.

Main conclusions: Functional traits are useful in connecting vegetation changes to the mechanisms that drive them, and provide unique information compared to turnover and diversity metrics. These trait-dependent selection effects could inform which
\end{abstract}

This is an open access article under the terms of the Creative Commons Attribution License, which permits use, distribution and reproduction in any medium, provided the original work is properly cited.

(c) 2021 The Authors. Global Ecology and Biogeography published by John Wiley \& Sons Ltd. 
species benefit and which suffer from land-use changes and explain observed biodiversity changes under global change.

\section{KEYWORDS}

community composition, forest management, large herbivores, plant size-diversity relationship, reindeer, species diversity, temporal change, vegetation resurvey

\section{1 | INTRODUCTION}

There is an urgent need to develop better tools for monitoring biodiversity change, as the most commonly used metrics, species richness and compositional turnover, do not capture its full extent (Blowes et al., 2019; Hillebrand et al., 2018). One way to move towards understanding the processes behind biodiversity change is to establish links between the functional composition of communities and potential selective forces, such as land-use change. Changes in average functional traits can be directly informative of changing selection pressures on communities and resulting ecosystem consequences (Lavorel \& Garnier, 2002; Violle et al., 2007). That is, if we knew how the functional composition of communities responded to anthropogenic pressures, we could use traits to monitor the effects of human actions on natural systems, and perhaps predict the resulting changes in ecosystem properties.

The above-ground traits of vascular plant species and communities have been found to vary on at least two important and independent axes: plant size and the leaf economics spectrum (LES). Size-related traits determine competitive hierarchies in relation to light, while leaf economic traits describe, for example, leaf construction costs and maximum photosynthetic output (Bruelheide et al., 2018; Díaz et al., 2016). Plant size is often described with vegetative height, and the LES with traits such as specific leaf area (SLA) and leaf dry matter content (LDMC) (van der Plas et al., 2020). When external drivers such as land-use change affect the optimal allocation of resources to vertical growth and to leaves, they are also expected to exert directional selection pressure on the composition of plant communities, which should manifest as changes in average functional traits.

Climate has traditionally been seen as the dominant driver of boreal biodiversity, while the impacts of other drivers such as large herbivores have been underestimated; yet they play a prominent role in community assembly (Pausas \& Bond, 2018). Large herbivores have strong impacts on vegetation that include favouring traits that decrease susceptibility to grazing, such as small size and unpalatable leaves (e.g. high LDMC and low SLA, Díaz et al., 2007). Nowadays wild megafauna has been partly replaced by human livestock (Hempson et al., 2017), and humans regulate herbivore densities. In many parts of Eurasia and North America reindeer/caribou (Rangifer tarandus) is herded as semi-domesticated free-ranging livestock. Reindeer grazing is known to cause declines in total plant biomass and in favoured forage species such as large herbs and deciduous shrubs in boreal and tundra environments (Bråthen \& Oksanen, 2001; Olofsson et al., 2010; Sundqvist et al., 2019). Evidence of the impact of large herbivores on plant traits exists from other systems (Cingolani et al., 2007; Díaz et al., 2007), but is very limited from the boreal zone and especially from its forested systems.

One third of global forested area belongs to the boreal zone, and a majority of it is used for industrial wood production (Gauthier et al., 2015). Management effects on ecosystems can lag decades behind changes in management practices (Muurinen et al., 2019), underlining the importance of long-term resurvey data for detecting biodiversity changes. Even though boreal forests are estimated to be highly sensitive to modern climate change (IPCC, 2018), the species compositions of both canopies and understories have shown relatively small long-term responses to climate change compared to land use (Danneyrolles et al., 2019; Tonteri et al., 2016). A possible reason for the weak climate change responses is that closed forest canopies can buffer microclimatic conditions in the understorey against macroclimatic warming (De Frenne et al., 2019). Trends in canopy cover can be affected by land-use histories, as disturbed tree-layers densen naturally when left alone, while new disturbances, such as logging, can increase temperature and light availability in the understorey (Tonteri et al., 2016). Changes in light availability should be reflected in SLA, which increases in response to shade (Dahlgren et al., 2006). A recent resurvey from European temperate forests shows increasing canopy shade to be the primary cause of changes in functional composition of herb-layers in these systems (Depauw et al., 2020), but the generality of this finding in other biomes remains untested.

The monitoring of average functional traits alongside diversity is also important because diversity is not independent of functional composition. It has long been known that high productivity can lead to decreased diversity (Grime, 1973). The unimodal productivitydiversity relationship is in part a mechanistic consequence of productivity increasing average species size, since communities composed of larger species have room for fewer plant individuals and therefore exhibit decreased diversity (Oksanen, 1996). Similar hypotheses regarding size-diversity relationships have been put forward and tested for other taxa as well (Siemann et al., 1996). Thus, in systems where human actions modify the selective landscape in relation to species size, anthropogenic disturbances are expected to also affect local diversity. For example, as discussed above, increased grazing pressure by livestock should proportionately favour smaller species and thus increase diversity (Jia et al., 2018). 
Because the processes that drive changes in plant communities may be spatially structured, changes in community properties may be as well. For example, diversity changes might be positive in some areas and negative in others, resulting in zero average change (Vellend et al., 2013). This needs to be taken into account when interpreting average changes, lest we fall victim to the ecological fallacy of assuming that all members of a population behave in the same way as the population on average (Robinson, 1950).

Here we study the temporal and spatial variation in diversity and community composition by analysing the long-term effects of two main land-use types (reindeer husbandry and forestry) and changes in canopies (canopy SLA and cover) on boreal herb-rich forest understories. By comparing diversity-, dissimilarity-, and functional traitbased approaches using hierarchical Bayesian regression modelling, we seek answers to four questions: (a) have species diversity, functional composition (measured as average height, SLA and LDMC), and species composition changed in boreal herb-rich forests over 40-50 years; (b) are there spatial differences in these changes; (c) are the changes related to changes in semi-domesticated reindeer abundance, forest management intensity, or changes in canopy SLA and cover; and finally (d) are the changes in functional composition correlated with changes in diversity across both time and space, hinting at processes that link traits to diversity?

\section{MATERIALS AND METHODS}

\subsection{Vegetation data and resampling}

We conducted a vegetation resurvey in boreal herb-rich forests in northern Finland (Figure 1). The resurveyed herb-rich forest sites were originally surveyed in 1968-1975 by Eero Kaakinen (Kaakinen, 1971, 1974, unpublished). The purpose of the original surveys was to identify phytosociological species associations in mature herb-rich forests. For this reason, the surveys were conducted in relatively undisturbed habitats. These forests harbour higher species richness than the surrounding less fertile and homogenous boreal forests (Maliniemi et al., 2019), are an important habitat for many threatened species (Kouki et al., 2018), and are thus important to monitor. They occur typically as small patches and cover only a fraction of the forested area in northern Scandinavia reflecting the scattered distribution of calcareous bedrock and soil. The field layer is dominated by herbs such as Geranium sylvaticum and Filipendula ulmaria, ferns such as Gymnocarpium dryopteris and Athyrium filixfemina, and graminoids such as Milium effusum and Elymus caninus. Occasionally, they also host species typical of less fertile boreal forests, such as the dwarf-shrubs Vaccinium myrtillus and Vaccinium vitis-idaea. The three most abundant tree species Picea abies, Alnus

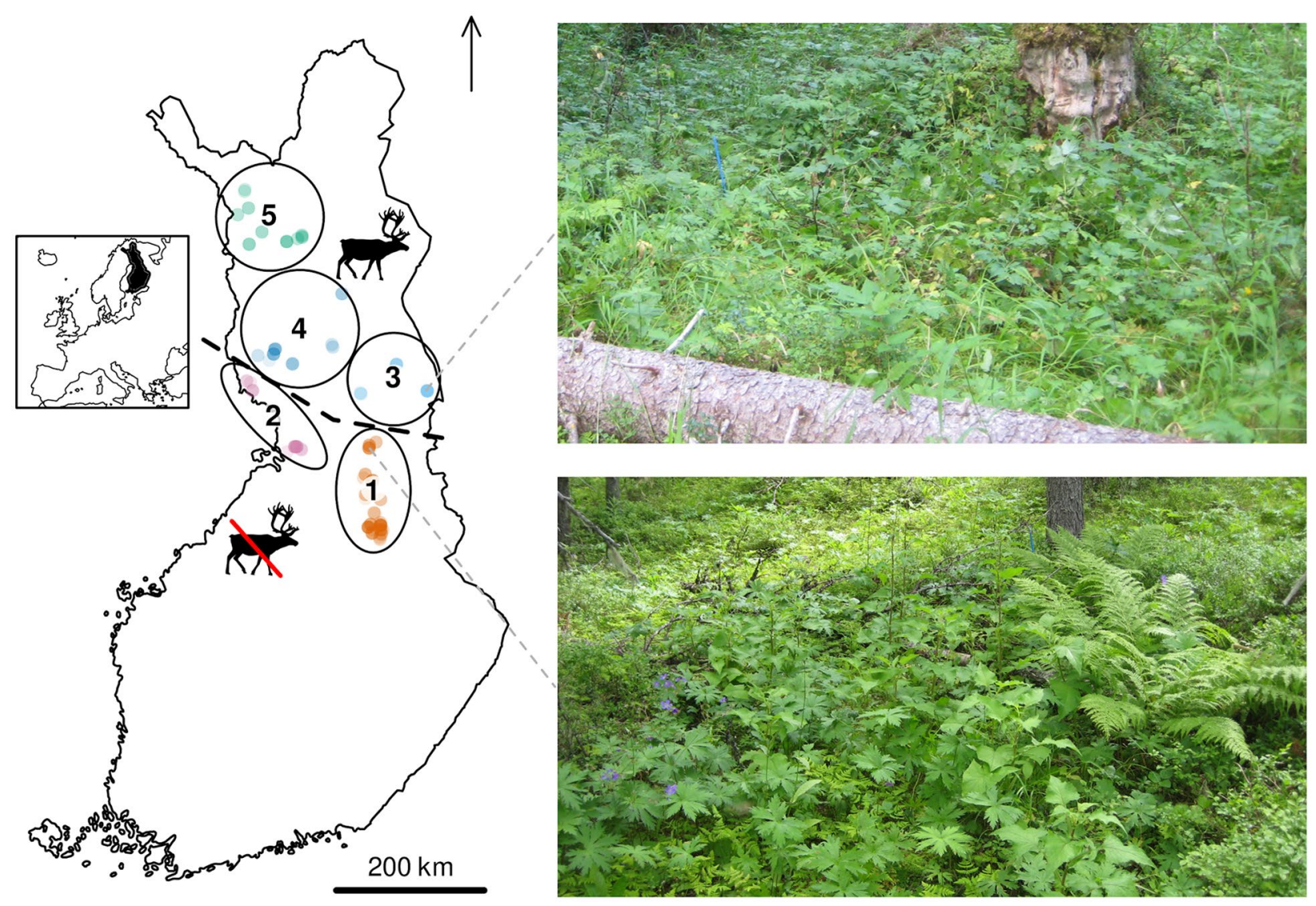

FIGURE 1 Map of the study area. The circles depict the biogeographical district (BGD) division used in this study. The line in the middle is the southern edge of the reindeer herding area. The images on the right depict typical vegetation in reindeer-grazed (upper) and ungrazed (lower) herb-rich forests. Basemap CC-BY National Land Survey of Finland [Colour figure can be viewed at wileyonlinelibrary.com] 
incana and Betula pubescens formed more than $80 \%$ of tree cover in our study plots, during both the original survey and the resurvey.

Using detailed notes on the locations of the original sites, we relocated and resurveyed a majority of the original 336 sites in 20132019. Most surveys were done in teams of $\geq 2$ investigators. We omitted sites that lacked detailed enough descriptions of location, and some sites that were located very far from other sites. The final number of plots, after applying the exclusion criteria described below, was 245 . Relocation error is inherent in vegetation resurveys (Kapfer et al., 2017), but was minimized as much as possible by the relocation help of the original surveyor, the patchy distribution of the studied vegetation type, and the fact that herb-rich forests are easily told apart from the boreal forest matrix. This study thus applies all of the measures listed by Verheyen et al. (2018) for minimizing observer and relocation error. During both the original survey and the resurvey, species composition was estimated from $5 \mathrm{~m} \times 5 \mathrm{~m}$ quadrats for the field layer and from $10 \mathrm{~m} \times 10 \mathrm{~m}$ quadrats for shrub and canopy layers. The smaller quadrats were nested in the larger quadrats. The abundances of field and shrub-layer species were estimated as absolute percentage covers, and the covers of tree-layer species were estimated as relative covers, that is, they always summed to $100 \%$. In addition, total canopy cover was estimated visually on a threepoint ordinal scale $(0-30,31-70,71-100 \%)$. In this study, we focus only on the vascular plants of the field and tree layers. Species in the shrub layer (woody species generally over $0.5 \mathrm{~m}$ but under $2 \mathrm{~m}$ tall) were excluded from analyses because they were measured at a different plot size compared to the field layer. We deemed this justified because the cover of such species was low (c. $2 \%$ on average). For species list and trait values, see Table S1.1 in Supporting Information Appendix S1.

\section{2 | Environmental changes}

We estimated forest management intensity during the resurvey based on the protocol used for the assessment of threatened habitat types in Finland (Kouki et al., 2018, p. 180). This protocol assigns sites on an ordinal scale of habitat quality ranging from 0 to 4 , describing absence of forest management impacts. Here, we inverted the scale to describe management intensity. We also omitted one site that was destroyed by deforestation and land conversion to arrive at a management impact variable ranging from 1 to 4 . The management intensity assessment criteria include the structure of the canopy and vegetation layers, disturbance of the soil, and the amount of deadwood, and are described in Supporting Information Appendix S2, Table S2.2. These criteria are applied in a one-out-allout manner, meaning that if any of the criteria for a more intensive management class were fulfilled, the site was assigned in that class even if it would have been a less intensively managed site based on all other criteria. The criteria are independent of the other variables used in this study, meaning that species composition and diversity were not used as measures of management intensity. Signs of forest management were present in c. $70 \%$ of the resurveyed plots, whereas the other c. 30\% were deemed unmanaged (Supporting Information Figure S2.1). Our observations in the field (including old stumps, plantations of c. 30-year-old trees, and old ditches) confirm that forest management was not concentrated near the second resampling, but was spread over a longer time period.

Reindeer are the major large grazer in our study area. In Finland, semi-domesticated reindeer occur only inside a designated reindeer herding area. Data on reindeer abundances in the different reindeer herding districts were provided by the Natural Resource Institute Finland. Reindeer densities in the herding area had increased c. $40 \%$ during the study period, from 1 to 1.4 reindeer $/ \mathrm{km}^{2}$ (Supporting Information Figure S2.2). We calculated 10-year average reindeer densities prior to each sampling time to be used as a predictor of vegetation changes. The population sizes of other large herbivores in the study area, as inferred from hunting statistics, are negligible (Natural Resources Institute Finland, 2020, Supporting Information Figure S2.1), with the exception of the moose (Alces alces). Although the moose population in Finland has grown due to changes in forestry practices and hunting, the growth has been rather uniform across the country (Nygrén, 2009). Moreover, herbaceous field layer vegetation constitutes less than $5 \%$ of moose summer diets (Hjeljord et al., 1990). Thus, while moose density changes might have affected forest regeneration and shrub layer composition, the direct effects of increased moose densities should be rather small and uniform across the study area. Contrarily, fertile herb-rich forests are a key foraging habitat for reindeer during summer, and we expect that changes in reindeer abundances over time can strongly affect trait composition and diversity of plant communities.

We included climate change in our analyses to test its potential effect on vegetation. Ten-year average minimum and maximum summer temperatures in our study plots have increased by 0.6 and $0.8^{\circ} \mathrm{C}$, respectively, in 45 years (1970-2015, Supporting Information Figure S2.4), and changes experienced by the field layer will have been buffered by the canopy layer (De Frenne et al., 2019). To avoid choosing between highly correlated maximum and minimum temperatures and implying that these interpolated variables carry more information than they do, we chose to explain vegetation responses to climate using 10-year average vapour pressure deficit (VPD) during the summer months from the Terra Climate dataset (Abatzoglou et al., 2018). VPD calculated in this way has a correlation of 0.9 and 1.0 with average minimum and maximum summer temperatures, respectively, from the same dataset, and has the added benefit of being defined in terms of average climatic conditions instead of thermal extremes. Averages were calculated from the years 1961-1970 for the original sample and the years 2006-2015 for the resample.

\section{3 | Community properties}

All data processing and analyses were done in $\mathrm{R}$ (version 4.0.5, R Core Team, 2019).

As species diversity measures, we calculated species richness, Shannon diversity, and species evenness. By Shannon 
TABLE 1 Structure of the expectation function of models used in this paper. All models had a Gaussian error distribution

\begin{tabular}{|c|c|c|}
\hline Response & Model & Model structure \\
\hline \multirow[t]{3}{*}{$\mathrm{E}($ Community property) } & 1 & a[time] \\
\hline & 2 & Model $1+\mathrm{b}[\mathrm{BGD}$, time $]+\mathrm{c}[$ plot $]$ \\
\hline & 3 & $\begin{array}{l}\text { Model } 2+\mathrm{CLI} \times \text { Climate change }+ \text { REI } \times \text { Reindeer } \\
\text { density change }+\mathrm{CSLA} \times \text { Canopy SLA change }+ \\
\text { CCOV }[\text { Canopy cover change }]+\text { MI }[\text { Management } \\
\text { intensity class }]\end{array}$ \\
\hline E(Evenness) & 4 & Model $3+\mathrm{HEI} \times$ Height change \\
\hline \multirow[t]{3}{*}{$\mathrm{E}$ (Turnover) } & 1 & a \\
\hline & 2 & Model $1+b[B G D]$ \\
\hline & 3 & $\begin{array}{l}\text { Model } 2+\mathrm{CLI} \times \text { Climate change }+\mathrm{REI} \times \text { Reindeer } \\
\text { density change }+\mathrm{CSLA} \times \text { Canopy SLA change }+ \\
\text { CCOV }[\text { Canopy cover change }]+\mathrm{MI}[\text { Management } \\
\text { intensity class }]\end{array}$ \\
\hline
\end{tabular}

Note: Community property refers to standardized species richness, species diversity, species evenness, and the abundance-weighted averages of log-transformed specific leaf area, leaf dry matter content and height. Turnover refers to standardized logit-transformed temporal Jaccard distance. See Materials and methods for descriptions of the different parameters (a, b, c, CLI, REI, CSLA, CCOV, MI, HEI). BGD = biogeographical district; LDMC = leaf dry matter content; SLA = specific leaf area. diversity we mean the so-called true diversity of order 1 , which is a unit conversion of the Shannon diversity index from entropy to species (Jost, 2006). As species evenness, we used Pielou's J, or the ratio of Shannon entropy to log-transformed species richness, which is a measure of relative evenness ranging from 0 to 1 (Jost, 2010).

We calculated community weighted means (CWMs) of logtransformed trait values for one size-structural trait and two leaf economic traits: vegetative height, specific leaf area (SLA) and leaf dry-matter content (LDMC). Trait values were log-transformed because generally, traits follow a log-normal distribution (Bjorkman et al., 2018). Species absolute covers were transformed to relative covers and used as weights. Trait values were retrieved from the TRY database (Kattge et al., 2020, version 5, 2011) and the LEDA database (Kleyer et al., 2008), and supplemented with our own measurements for common species that were not found in the databases. In four plots, some of the traits were available for less than $80 \%$ of total cover. These plots were excluded from analyses. In the remaining plots, trait values were available for $>99.5 \%$ of total cover for all traits. References to the original trait datasets are listed in Supporting Information Appendix S3.

We also calculated a CWM for the SLA of the canopy layer. SLA was not available for the non-native Larix sibirica (present on one site), for which we used the SLA of Larix decidua instead.

Summary statistics of the plant community properties during the original sampling c. 1970 are presented in Supporting Information Tables S2.3 and S2.4, which help in interpreting the observed rates of change.

We used the R package vegan (version 2.5-6, Oksanen et al., 2019) to calculate temporal turnover in community composition using the version of Jaccard distance that takes into account species abundances. Plot-scale turnover was logit-transformed before analyses to satisfy the assumption of homoskedasticity. We also calculated temporal turnover for the entire dataset.

\section{4 | Modelling}

We used those sites for which we had the full set of both response variables (species richness, species diversity, species evenness, height, LDMC and SLA) and predictor variables (canopy cover and canopy SLA, reindeer densities, management intensity and climate). The final dataset thus consisted of 245 resampled sites. These sites were then assigned to five biogeographical districts (BGDs, Figure 1) based on the Finnish biogeographical province division. Assignment to BGDs was done to account for spatially structured confounding variables in modelling. The original provinces were slightly modified for this study by merging districts with very few plots with neighbouring districts, and by moving plots between districts so as to make each district either completely within or outside the reindeer herding area.

We used hierarchical Bayesian regression models to analyse plot-level changes in species diversity and composition. Two kinds of models were deployed based on the nature of the response variable. For species richness, evenness, diversity, and the three functional trait composition variables, the response variables could be modelled as a function of time, whereas temporal turnover could only be modelled with spatially varying effects, because turnover already represents the difference between two timepoints. We built four models with increasing complexity to answer our stated questions. Model 1 investigates how diversity and composition have changed in the sampled forests on average. Model 2 studies if there is spatial variation in these vegetation changes. Model 3 tests if temporal trends in vegetation are related to changes in land use, climate, and 


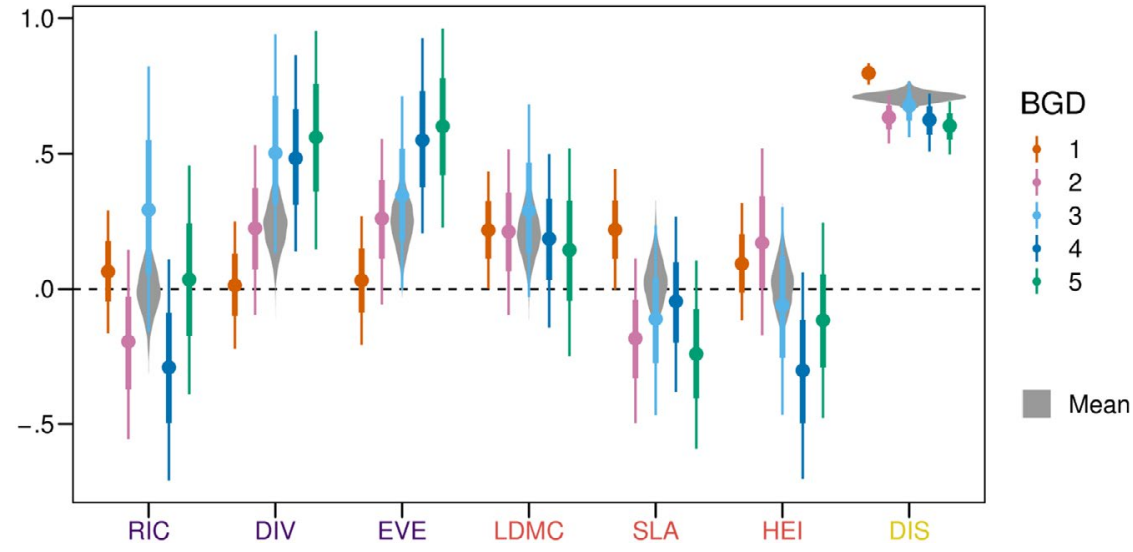

FIGURE 2 Temporal changes (1968-2019) in boreal herb-rich forest understorey species richness (RIC), Shannon diversity (DIV), species evenness (EVE), leaf dry matter content (LDMC), specific leaf area (SLA) and height (HEI), and average turnover (DIS), across the biogeographical districts (BGDs), as inferred from Model 2. The points are medians, the narrow and thick lines are 2/3 and 20/21 credible intervals, respectively, corresponding to $2 / 1$ and $20 / 1$ odds for the true parameter value to lie within the given interval, or 66.67 and $95.24 \%$ probability. The grey violin plots in the background are kernel density plots of the posterior distributions of average changes across all plots as inferred from Model 1. All response variables except DIS are shown on a standardized scale. BGDs are arranged according to their latitude, from south (1) to north (5) [Colour figure can be viewed at wileyonlinelibrary.com]

canopies. Finally, Model 4 studies if changes in species diversity are related to changes in functional composition. Because there were no average changes in species richness, and because species diversity is the product of richness and evenness, trends in diversity could not be strongly driven by changes in richness. Model 4 was thus only fitted for evenness. As average species size is directly related to the productivity and physical structure of the community, the model includes average species height as the only predictor describing functional composition. All responses were standardized by subtracting the mean and dividing by the standard deviation before analyses. The structure for the expectation function of different models is presented in Table 1. Note that responses (with the exception of turnover) were fed into the model separately for each time period, that is, changes in diversity and functional composition were not pre-calculated. This was done to allow pooling of information across time and space, and to describe the data-generating process as accurately as feasible.

All models assumed a Gaussian error distribution. In the models in Table 1, parameters b and c are BGD- and plot-level (random) effects, respectively. In models of composition and diversity, b pools information across space and time, so that all BGD-level effects within a sampling time (i.e. original survey or resurvey) are shrunk towards a common mean, and BGD-level effects in different sampling times correlate with each other. The parameter $c$ pools information across plots to shrink plot-level effects towards a common mean. In models of turnover, b pools information across BGDs. CLI, REI, CSLA, CCOV, MI, and HEI are the parameters that define the effects of the explanatory variables (climate change, reindeer density change, canopy SLA change, canopy cover change, management intensity, and vegetation height change) on the plant community properties.

To look at the total effects of forest management, we also built a model that left out changes in canopy cover and canopy SLA.
Because the results of this model were very similar to those of Model 3, we only present results for Model 3.

In Models 3 and 4 of community properties, all environmental and land-use terms were set to 0 for the original sample. Thus, the terms that are in Model 3 but not in Model 2 only affect composition in the resample. The continuous variables Climate change, Reindeer density change, Canopy SLA change and Height change were entered as a difference in the relevant quantity between the resurvey and the original survey, and their parameter estimates thus describe changes in the community-level property if the given predictor increases by one standardized unit in time. Management intensity was entered as a categorical variable with four levels, and canopy cover change was entered as a factor with three levels: decrease, no change, increase. The effect of no canopy cover change was fixed to 0 .

Bayesian hierarchical models were built using the R package for Bayesian modelling rethinking (version 2.11, McElreath, 2020), an interface to the probabilistic programming language Stan (Carpenter et al., 2017). In all models, coefficients for continuous variables were given a Normal $(0,0.5)$ prior distribution, coefficients for categorical variables were given a Normal $(0,1)$ prior distribution, all standard deviations were given an Exponential(1) prior distribution, and temporal correlations in the BGD-level random effect were given an LKJ(2) prior. There were no divergent transitions in any of the Markov chains in any of our models, which would have indicated unreliable estimates of the parameter posterior distributions (Carpenter et al., 2017). In addition, all parameters converged to a stationary posterior distribution (split chain R-hat $<1.01$ ).

To test whether vegetation height is related to evenness in time (modelled above) as well as in space, we modelled evenness as a function of height using a generalized additive model (Wood, 2011). The effect of height was entered as a thin plate spline with basis dimension 20 . We also tested whether the height-evenness relationship 
was different between sampling times (whether there was a timeheight interaction), but a comparison of Akaike information criterion (AIC) values indicated this was not the case.

\section{3 | RESULTS}

\subsection{Question a: Overall vegetation changes}

Examining average values across all biogeographical districts we detected no changes in species richness, but observed increases in plot-level Shannon diversity and evenness during the sampling interval. Average LDMC increased, but there was no detectable change in average species SLA or height (Figure 2). Average plot-scale turnover between the sampling periods was about 71\% (Figure 2). For the full dataset (i.e. the relative abundances of all species across the study area), temporal Jaccard dissimilarity was $37 \%$, which, when divided over the average sampling interval (44 years) using the equation for exponential decay (long-term turnover $\left.=1-(1 \text { - annual turnover })^{44}\right)$, corresponded to an annual turnover of $2.2 \%$.

\subsection{Question b: Geographical variation in vegetation changes}

Vegetation changes across the study area were not representative of changes in all the BGDs (Figure 2). Increases in species diversity and evenness had a clear geographical trend, with no changes in the south and clear increases in the north. Height changes also had a weak latitudinal gradient, with uncertain increases in height associated with more southern areas, and vice versa for the north. Patterns in species richness and SLA change and turnover were more idiosyncratic with respect to geography. Changes in LDMC did not differ geographically, but increased uniformly in all the BGDs.

\subsection{Question c: Causes of vegetation changes}

There was no discernible effect of observed climate change on any of the studied variables (Figure 3a).

Increasing reindeer densities were associated with increasing species diversity, evenness and LDMC, and decreased SLA and height (Figure 3b). In addition, plots within the reindeer herding area had more positive trends in diversity and evenness and more negative trends in height compared to those outside the reindeer herding area.

Forest management negatively affected species richness, and increased temporal turnover compared to unmanaged forests (Figure 3c). The responses were reinforced by increasing management intensity. Temporal trends in trait composition were only weakly related to forest management. SLA showed a tendency to increase and LDMC a tendency to decrease in the most intensively managed sites compared to natural sites. Unmanaged forests had an uncertain positive richness trend, with a mean change of +0.3 standardized units and an $80 \%$ probability of the trend being positive.

Changes in canopy SLA correlated negatively with field-layer SLA and temporal turnover (Figure 3d). Canopy SLA changes were almost completely explained by changes in the dominance of the evergreen tree Picea abies (Supporting Information Figure S2.5), with P. abies dominance corresponding to decreasing canopy SLA.

Canopy cover changes also affected these communities, with increasing and decreasing canopy covers changing communities in different directions (Figure 3e). Changes in canopy cover were positively correlated with changes in diversity, evenness and SLA, and negatively with changes in LDMC and height.

\subsection{Question d: Effect of height on diversity change}

Height had a nonlinear but mostly negative spatial relationship with evenness (Figure 4a). The temporal relationship between height and evenness was also negative (Figure $4 \mathrm{~b}$ ). Including height as a predictor somewhat decreased the inferred effects of reindeer and canopy cover changes on evenness (Supporting Information Figure S2.7).

\section{4 | DISCUSSION}

We found that land-use, but not climate change, alters the functional composition of forest understorey plant communities and explains part of the variation in temporal biodiversity trends both at regional and fine scales. Most evidently, increased reindeer densities had a clear effect on both average plant functional traits and diversity measures. Reindeer decreased average SLA and decreased plant height, which resulted in increased species evenness and diversity. Our findings show that diversity changes were partially modulated by changes in plant size, illustrating a direct effect of changing functional composition on diversity. Our results thus highlight the way changes in average traits can be informative of changing selection pressures on vegetation, as most observed changes in functional composition were directly linked to land-use and canopy changes in ways that are consistent with theory. We thus provide evidence that including functional metrics in biodiversity monitoring programmes is useful for inferring causes of biodiversity changes during the Anthropocene (Pereira et al., 2013).

\section{1 | Vegetation trends vary in space}

Our analysis revealed that many community characteristics were stable over the 4-5 decade study interval across the study area, but displayed trends when vegetation changes were conditioned on geographical location. Diversity, evenness, and vegetation height had different trends in different parts of the latitudinal gradient. Apparent stability at larger scales can thus be the sum of opposing 
(a)
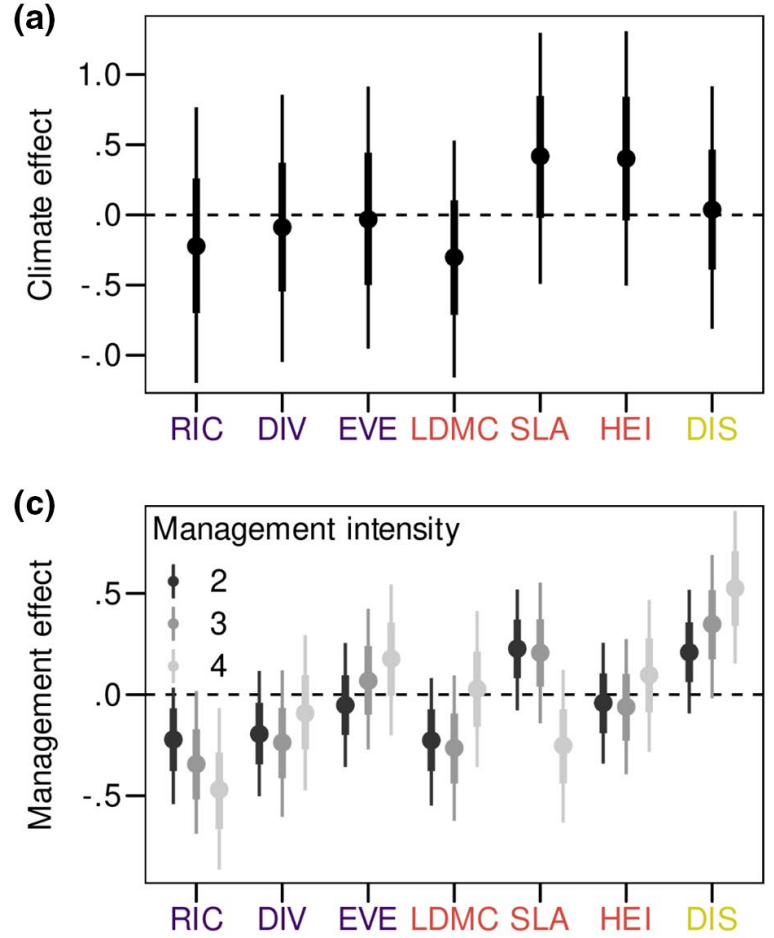
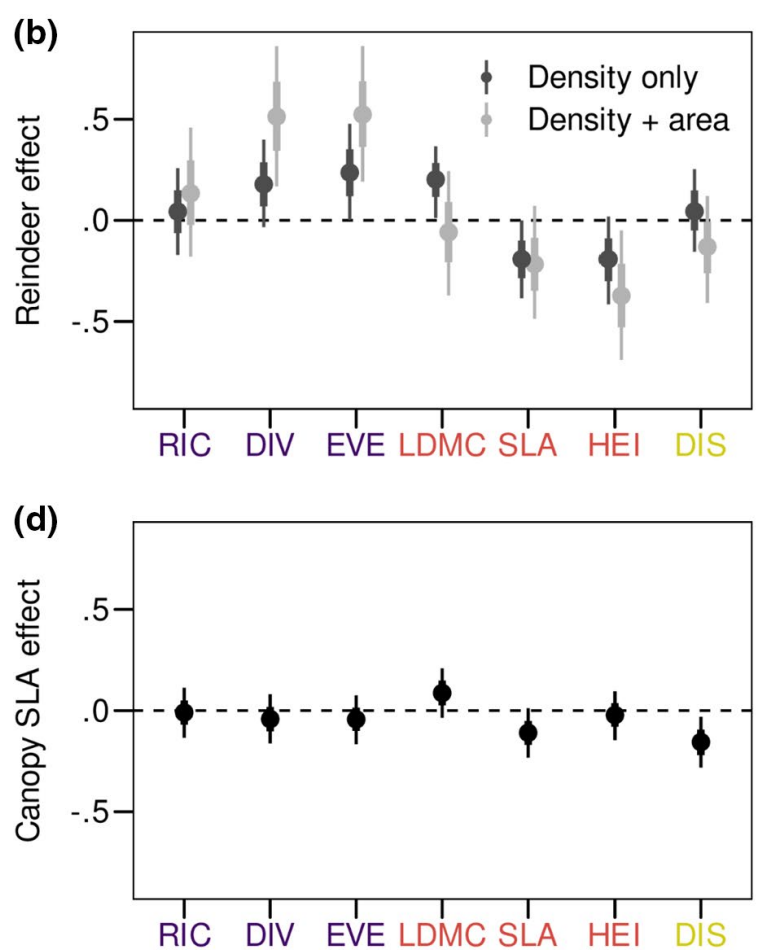

(e)

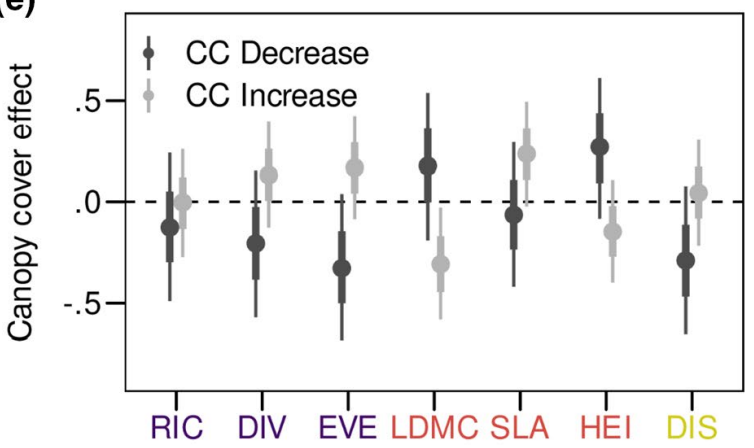

FIGURE 3 Standardized direct effects of climate change (a), reindeer (b), forest management intensity (c), canopy specific leaf area (SLA) increase (d), and canopy cover change (e) on community-level properties and turnover in boreal herb-rich forest understories, as inferred from Model 3. Reindeer effects are displayed as the direct effect of reindeer density change and the combined effects of density change and being situated inside the reindeer herding area (average difference in trend compared to a plot outside the area). Management intensity effects are contrasts against unmanaged forests (intensity class 1 ). The points are medians, the narrow and thick lines are $2 / 3$ and $20 / 21$ credible intervals, respectively, corresponding to $2 / 1$ and $20 / 1$ odds for the true parameter value to lie within the given interval. Response abbreviations as in Figure 2. Traits were log-transformed and turnover logit-transformed before analyses [Colour figure can be viewed at wileyonlinelibrary.com]

trends in different regions. We report that across the study area, species richness was on average stable as in a previous meta-analysis (Vellend et al., 2013), even though species turnover was on average very high (c. 70\%). Our results are thus consistent with the hypothesis that local species richness is highly constrained by regional processes such as compensatory colonization-extinction dynamics, meaning that lost species are readily replaced by new species from the metacommunity (Supp \& Ernest, 2014). Average turnover within plots was high, most likely attributable to high species richness (Supporting Information Table S2.3), a long sampling interval, and inherent relocation error. Nonetheless, temporal turnover for the full dataset was of the same magnitude as average turnover in terrestrial ecosystems in a recent meta-analysis ( $2 \%$ per year, Blowes et al., 2019), showing that the rate of compositional change in our data is representative of previously reported biodiversity changes.

\subsection{Land-use and canopy dynamics change the composition of field-layer vegetation}

Our results provide clear evidence that reindeer control forest community composition by diminishing the relative abundance of tall plants with high SLA, thereby increasing species diversity, expanding the earlier findings from tundra and mountain forests (Kaarlejärvi et al., 2017; Sundqvist et al., 2019) to boreal forests. These findings are consistent with theoretical expectations, since SLA has 

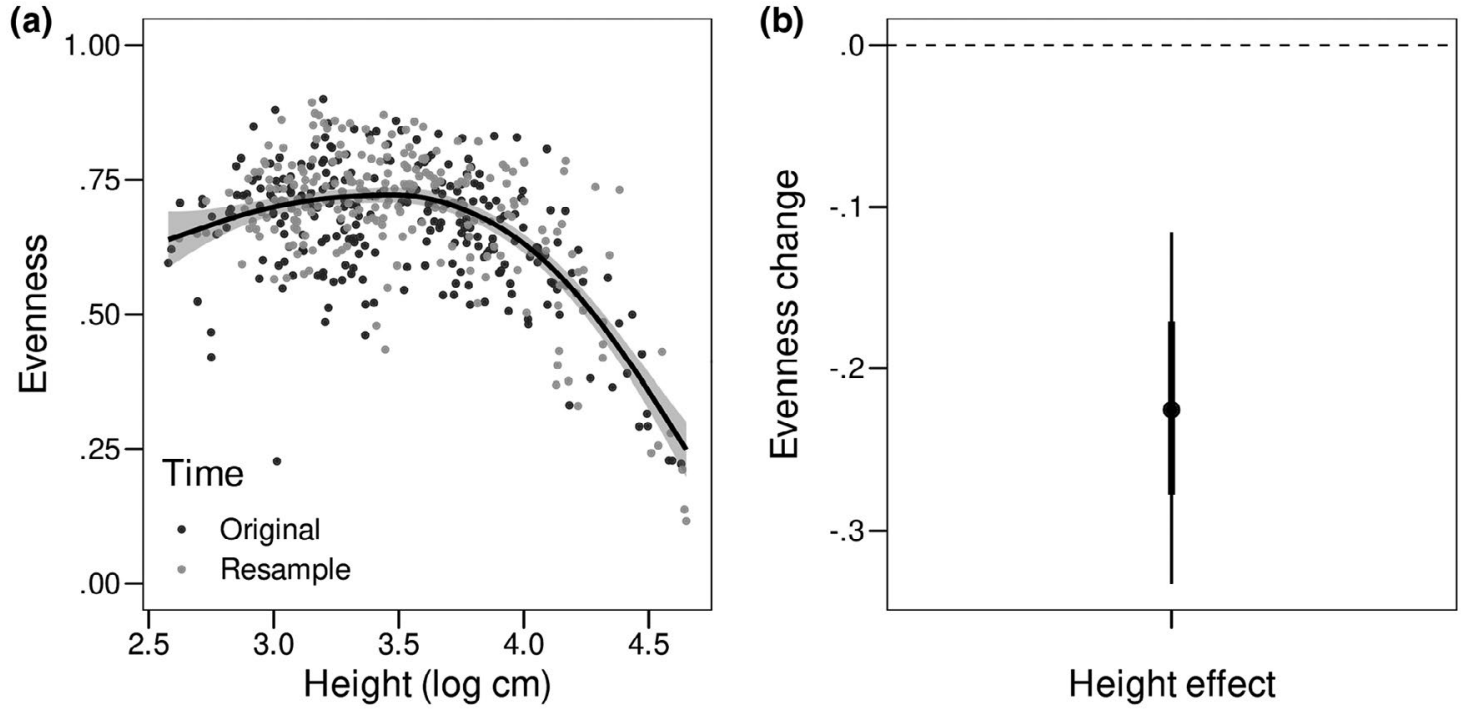

FIGURE 4 Spatial (a) and temporal (b) relationships between community evenness and average plant height. The spatial relationship is an unadjusted generalized additive model (GAM) of evenness against height. The temporal effect is a marginal standardized effect from hierarchical linear Model 4 (see Materials and methods). In (a), the line is the mean effect and the shading is the 20/21 confidence interval. In (b), the point is the median effect, and the narrow and thick lines are 2/3 and 20/21 credible intervals, respectively. Refer to Materials and methods for more information

been shown to correlate positively with nutrient concentrations in leaves (i.e. forage quality, Díaz et al., 2016), while large plants have been shown to be more susceptible to mammalian herbivory (Díaz et al., 2007). Furthermore, reindeer presence in itself seemed to affect vegetation changes even when animal densities remained the same, since changes in vegetation height and diversity were more pronounced in BGDs that were inside the reindeer herding area (BGDs 3, 4 and 5, Figure 3). However, these effects could also be related to other confounding factors that change along the latitudinal gradient.

Surprisingly, forest management intensity did not have clear effects on functional composition. Instead, it decreased species richness and increased turnover. Forest management effects on turnover and diversity were mostly direct, that is, not mediated by management effects on canopy cover and composition, as evidenced by the small difference between management effects in models that included versus excluded canopy variables. The finding of higher turnover in managed forests agrees with previous studies from boreal forests (Brice et al., 2019; Kaarlejärvi et al., 2021) and other biomes (Barlow et al., 2016; Lake et al., 2000) reporting accelerated biodiversity change following human disturbance. Taken together, our results suggest that species richness changes in vascular plant communities in response to forest management do not seem to be driven by a filtering of species based on plant height or leaf traits. However, the highest management intensity class (class 4) that included recent clearcuts had more negative SLA and more positive LDMC trends compared to other managed forests, which supports previous findings of harvesting having a signal on the light-interception strategy of the understorey community (Tonteri et al., 2016), but suggests that this effect is transient and undetectable in later forest development phases.
Canopy development also affected functional composition. Canopy cover had increased on average (see Supporting Information Figure S2.6), leading to increased shading and decreased abundance of tall, light-demanding species with high SLA and low LDMC. SLA is a succession trait, which increases in response to shade (Dahlgren et al., 2006), whereas LDMC has probably decreased because of its negative covariance with SLA (Bruelheide et al., 2018). Canopy composition, expressed as canopy SLA, also influenced the functional composition of the understorey. We would have expected changes in canopy SLA to correlate positively with nutrient availability and thus also with fast leaf economic traits (i.e. high SLA, low LDMC). Instead, we found the opposite. In our data, canopy SLA was almost perfectly negatively correlated with the relative abundance of $P$. abies (see Supporting Information Figure S2.5), which is the only abundant evergreen tree in these systems and frequently forms monodominant stands. This lack of diversity at one end of the trait spectrum limits the usefulness of functional traits in inferring the mechanisms by which canopy composition affects understories, since average trait metrics become perfectly correlated with all qualities of $P$. abies. We hypothesize that in our data, the true mechanism behind the connection between canopy SLA and functional composition is increased shading with increasing $P$. abies dominance. Picea abies is evergreen and very shade tolerant, its canopy extends further down than that of other large trees, and it casts shade also during spring and autumn, when deciduous species are without leaves. This hypothesis is supported by the similar functional footprint of canopy SLA and shading on understories (decreased SLA, increased LDMC). The fact that decreased canopy SLA, through increased P. abies dominance, was associated with increased community turnover agrees with previous literature that lists 'borealization' as one threat against understories of semi-open, mixed or deciduous canopies (Kouki et al., 


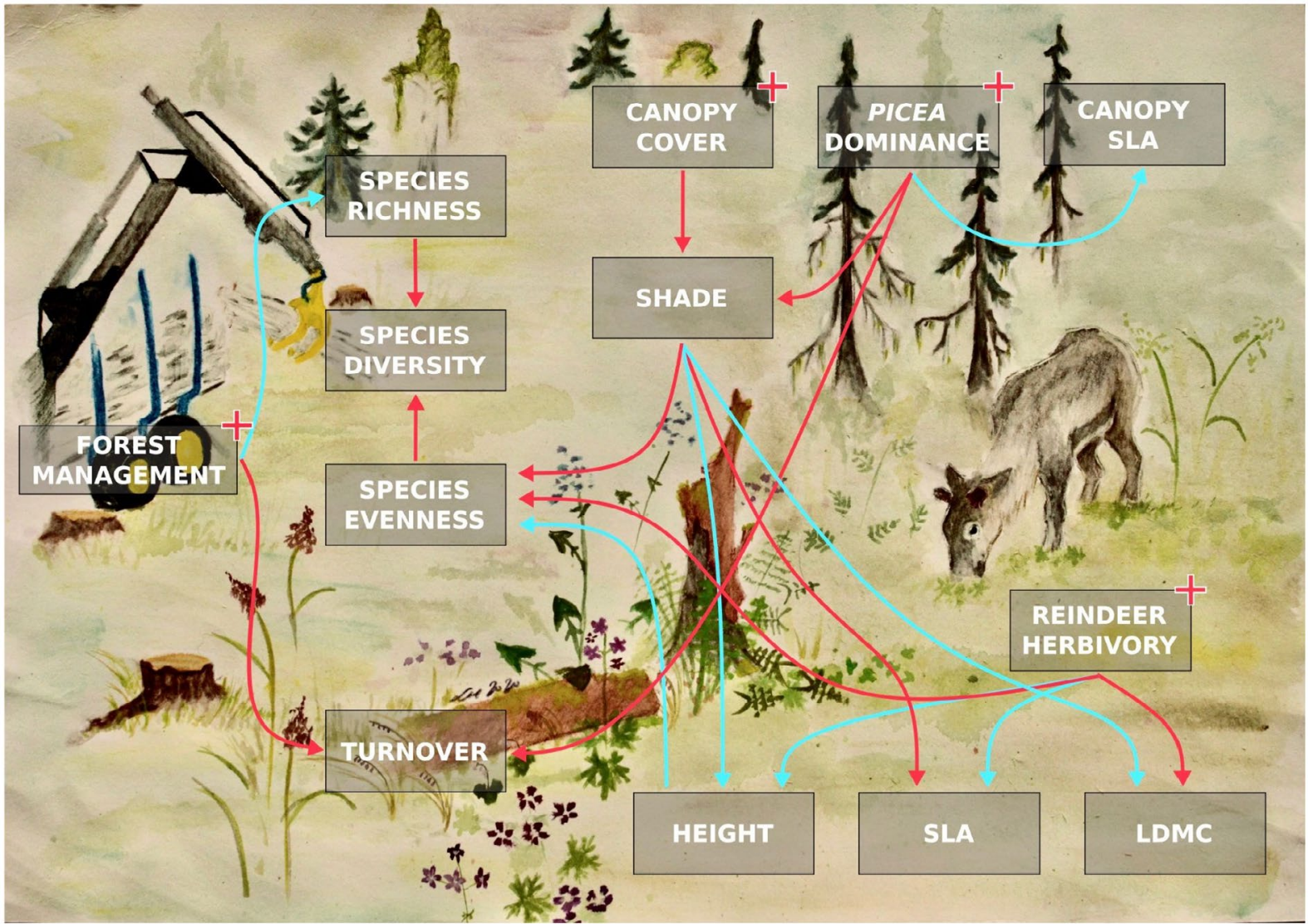

FIGURE 5 A conceptual model of vegetation change drivers in these boreal forests. Red lines correspond to positive effects, and blue lines to negative effects. Positive trends in land-use and canopy variables are marked with red plus signs. While based on our modelling results, the arrows are our subjective interpretation of their implications. LDMC = leaf dry matter content; SLA = specific leaf area [Colour figure can be viewed at wileyonlinelibrary.com]

2018). Moreover, our results support the findings of a recent resurvey study from European temperate forests, which listed increasing canopy shade as the primary cause of changes in functional composition of herb-layers (Depauw et al., 2020), thereby generalizing these results across the temperate-boreal boundary.

\section{3 | Changes in diversity are partially mediated by vegetation height}

Changes in species diversity were mostly caused by changes in evenness, and those in turn were directly related to changes in vegetation height and its environmental drivers, namely reindeer herbivory and changes in canopy cover. Furthermore, the relationship between evenness and plant height was consistent across both space and time, providing further evidence that changes in functional composition can be a direct mechanism behind diversity changes. Reindeer grazing and canopy cover effects are most likely results of the mechanistic link between size and diversity: tall species are being eaten or suppressed by lack of light, which reduces dominance, which in turn increases diversity (Grime, 1973; Oksanen, 1996). In these forests, both canopy cover and reindeer densities have increased on average. According to our results, both these changes favour shorter plants and result in increased evenness and diversity, thus partially explaining the observed large-scale changes in diversity. These results agree with Depauw et al. (2020), who also found that increased shading is responsible for increased evenness in the herb-layers of temperate European forests.

The effects of reindeer and canopy variables on evenness were not fully mediated by vegetation size (Supporting Information Figure S2.7), because reindeer still had effects on diversity after adjusting for changes in plant height (Model 4). One explanation may be that our study does not account for intraspecific changes in height, which could happen in response to altered light availability or grazing pressure (Jessen et al., 2020). Thus, the effects of reindeer herbivory and canopy cover on evenness via vegetation height are probably even stronger than detected here.

\section{5 | CONCLUSIONS}

Herbivory and canopy properties affect the diversity and composition of understorey plant communities in boreal herb-rich forests over several decades (Figure 5). Our results illustrate that land-use 
and canopy changes impact diversity indirectly by affecting average plant height. By favouring smaller species and limiting the size of plant individuals, increased shade and grazing pressure increase diversity. Therefore, plant size has a mechanistic connection with diversity. In addition, high light availability and reindeer densities favour slower leaf economic traits. Our results thus confirm that functional traits are both indicators and mediators of land-use change effects on plant communities, and underline the importance of including functional metrics in biodiversity monitoring programmes.

\section{ACKNOWLEDGMENTS}

The authors thank Jouko Kumpula from the Natural Resources Institute Finland for providing the reindeer density data. The authors acknowledge funding from Societas Pro Fauna et Flora Fennica, Societas Biologica Fennica Vanamo, Societas Amicorum Naturae Ouluensis, Academy of Finland (project \#259072), Finnish Cultural Foundation, The Finnish Society of Forest Science and Jane \& Aatos Erkko Foundation. The authors also thank Anu Skog and Niilo Tenkanen for help with fieldwork, and are grateful for the Botanical Museum and Oulanka Research station of the University of Oulu for providing facilities.

\section{DATA AVAILABILITY STATEMENT}

The data and scripts used to produce these results have been deposited in Zenodo (Happonen et al., 2021).

\section{ORCID}

Konsta Happonen (DD https://orcid.org/0000-0002-3164-8868 Elina Kaarlejärvi (iD https://orcid.org/0000-0003-0014-0073 Tuija Maliniemi iD https://orcid.org/0000-0003-1218-6554

\section{REFERENCES}

Abatzoglou, J. T., Dobrowski, S. Z., Parks, S. A., \& Hegewisch, K. C. (2018). TerraClimate, a high-resolution global dataset of monthly climate and climatic water balance from 1958-2015. Scientific Data, 5, 170191. https://doi.org/10.1038/sdata.2017.191

Barlow, J., Lennox, G. D., Ferreira, J., Berenguer, E., Lees, A. C., Mac Nally, R., Thomson, J. R., de Barros Ferraz, S. F., Louzada, J., Oliveira, V. H. F., Parry, L., Ribeiro de Castro Solar, R., Vieira, I. C. G., Aragão, L. E. O. C., Begotti, R. A., Braga, R. F., Cardoso, T. M., de Oliveira, R. C. Jr, Souza, C. M. Jr, ... Gardner, T. A. (2016). Anthropogenic disturbance in tropical forests can double biodiversity loss from deforestation. Nature, 535(7610), 144-147. https://doi.org/10.1038/nature18326

Bjorkman, A. D., Myers-Smith, I. H., Elmendorf, S. C., Normand, S., Thomas, H. J. D., Alatalo, J. M., Alexander, H., Anadon-Rosell, A., Angers-Blondin, S., Bai, Y., Baruah, G., te Beest, M., Berner, L., Björk, R. G., Blok, D., Bruelheide, H., Buchwal, A., Buras, A., Carbognani, M., ... Zamin, T. (2018). Tundra Trait Team: A database of plant traits spanning the tundra biome. Global Ecology and Biogeography, 27(12), 1402-1411. https://doi.org/10.1111/geb.12821

Blowes, S. A., Supp, S. R., Antão, L. H., Bates, A., Bruelheide, H., Chase, J. M., Moyes, F., Magurran, A., McGill, B., Myers-Smith, I. H., Winter, M., Bjorkman, A. D., Bowler, D. E., Byrnes, J. E. K., Gonzalez, A., Hines, J., Isbell, F., Jones, H. P., Navarro, L. M., ... Dornelas, M. (2019). The geography of biodiversity change in marine and terrestrial assemblages. Science, 366(6463), 339-345. https://doi.org/10.1126/ science.aaw1620
Bråthen, K. A., \& Oksanen, J. (2001). Reindeer reduce biomass of preferred plant species. Journal of Vegetation Science, 12(4), 473-480. https://doi.org/10.2307/3236999

Brice, M., Cazelles, K., Legendre, P., \& Fortin, M. (2019). Disturbances amplify tree community responses to climate change in the temperateboreal ecotone. Global Ecology and Biogeography, 28(11), 1668-1681. https://doi.org/10.1111/geb.12971

Bruelheide, H., Dengler, J., Purschke, O., Lenoir, J., Jiménez-Alfaro, B., Hennekens, S. M., Botta-Dukát, Z., Chytrý, M., Field, R., Jansen, F., Kattge, J., Pillar, V. D., Schrodt, F., Mahecha, M. D., Peet, R. K., Sandel, B., van Bodegom, P., Altman, J., Alvarez-Dávila, E., ... Jandt, U. (2018). Global trait-environment relationships of plant communities. Nature Ecology \& Evolution, 2(12), 1906-1917. https://doi.org/10.1038/ s41559-018-0699-8

Carpenter, B., Gelman, A., Hoffman, M. D., Lee, D., Goodrich, B., Betancourt, M., Brubaker, M. A., Guo, J., Li, P., \& Riddell, A. (2017). Stan: A probabilistic programming language. Journal of Statistical Software, 76(1), 1-32. https://doi.org/10.18637/jss.v076.i01

Cingolani, A. M., Cabido, M., Gurvich, D. E., Renison, D., \& Díaz, S. (2007). Filtering processes in the assembly of plant communities: Are species presence and abundance driven by the same traits? Journal of Vegetation Science, 18(6), 911-920. https://doi.org/10.1111/ j.1654-1103.2007.tb02607.x

Dahlgren, J. P., Eriksson, O., Bolmgren, K., Strindell, M., \& Ehrlén, J. (2006). Specific leaf area as a superior predictor of changes in field layer abundance during forest succession. Journal of Vegetation Science, 17(5), 577-582. https://doi.org/10.1111/j.1654-1103.2006. tb02481.x

Danneyrolles, V., Dupuis, S., Fortin, G., Leroyer, M., de Römer, A., Terrail, R., Vellend, M., Boucher, Y., Laflamme, J., Bergeron, Y., \& Arseneault, D. (2019). Stronger influence of anthropogenic disturbance than climate change on century-scale compositional changes in northern forests. Nature Communications, 10(1), 1265. https://doi. org/10.1038/s41467-019-09265-z

De Frenne, P., Zellweger, F., Rodríguez-Sánchez, F., Scheffers, B. R., Hylander, K., Luoto, M., Vellend, M., Verheyen, K., \& Lenoir, J. (2019). Global buffering of temperatures under forest canopies. Nature Ecology \& Evolution, 3(5), 744-749. https://doi.org/10.1038/s4155 9-019-0842-1

Depauw, L., Perring, M. P., Landuyt, D., Maes, S. L., Blondeel, H., De Lombaerde, E., Brūmelis, G., Brunet, J., Closset-Kopp, D., Czerepko, J., Decocq, G., den Ouden, J., Gawryś, R., Härdtle, W., Hédl, R., Heinken, T., Heinrichs, S., Jaroszewicz, B., Kopecký, M., ... Verheyen, K. (2020). Light availability and land-use history drive biodiversity and functional changes in forest herb layer communities. The Journal of Ecology, 108(4), 1411-1425. https://doi.org/10.1111/1365-2745.13339

Díaz, S., Kattge, J., Cornelissen, J. H. C., Wright, I. J., Lavorel, S., Dray, S., Reu, B., Kleyer, M., Wirth, C., Colin Prentice, I., Garnier, E., Bönisch, G., Westoby, M., Poorter, H., Reich, P. B., Moles, A. T., Dickie, J., Gillison, A. N., Zanne, A. E., ... Gorné, L. D. (2016). The global spectrum of plant form and function. Nature, 529(7585), 167-171. https:// doi.org/10.1038/nature16489

Díaz, S., Lavorel, S., Mclntyre, S., Falczuk, V., Casanoves, F., Milchunas, D. G., Skarpe, C., Rusch, G., Sternberg, M., Noy-Meir, I., Landsberg, J., Zhang, W., Clark, H., \& Campbell, B. D. (2007). Plant trait responses to grazing-a global synthesis. Global Change Biology, 13(2), 313-341. https://doi.org/10.1111/j.1365-2486.2006.01288.x

Gauthier, S., Bernier, P., Kuuluvainen, T., Shvidenko, A. Z., \& Schepaschenko, D. G. (2015). Boreal forest health and global change. Science, 349(6250), 819-822. https://doi.org/10.1126/scien ce.aaa9092

Grime, J. P. (1973). Competitive exclusion in herbaceous vegetation. Nature, 242(5396), 344-347. https://doi.org/10.1038/242344a0

Happonen, K., Muurinen, L., Virtanen, R., Kaakinen, E., Parisot, P., Wolff, M., \& Maliniemi, T. (2021). Data and code for the paper 
"Trait-based responses to forestry and reindeer husbandry modify longterm changes in forest understories.". Zenodo. https://doi.org/10.5281/ zenodo.4432158

Hempson, G. P., Archibald, S., \& Bond, W. J. (2017). The consequences of replacing wildlife with livestock in Africa. Scientific Reports, 7(1), 17196. https://doi.org/10.1038/s41598-017-17348-4

Hillebrand, H., Blasius, B., Borer, E. T., Chase, J. M., Downing, J. A., Eriksson, B. K., Filstrup, C. T., Harpole, W. S., Hodapp, D., Larsen, S., Lewandowska, A. M., Seabloom, E. W., Van de Waal, D. B., \& Ryabov, A. B. (2018). Biodiversity change is uncoupled from species richness trends: Consequences for conservation and monitoring. The Journal of Applied Ecology, 55(1), 169-184. https://doi. org/10.1111/1365-2664.12959

Hjeljord, O., Hovik, N., \& Pedersen, H. B. (1990). Choice of feeding sites by moose during summer, the influence of forest structure and plant phenology. Ecography, 13(4), 281-292. https://doi.org/10.1111/ j.1600-0587.1990.tb00620.x

IPCC. (2018). Summary for policymakers. In V. Masson-Delmotte, P. Zhai, H.-O. Pörtner, D. Roberts, J. Skea, P. R. Shukla A. Pirani W. Moufouma-Okia C. Péan R. Pidcock S. Connors J. B. R. Matthews Y. Chen X. Zhou M. I. Gomis E. Lonnoy T. Maycock M. Tignor \& T. Waterfield (Eds.), Global warming of $1.5^{\circ} \mathrm{C}$. An IPCC Special Report on the impacts of global warming of $1.5^{\circ} \mathrm{C}$ above pre-industrial levels and related global greenhouse gas emission pathways, in the context of strengthening the global response to the threat of climate change, sustainable development, and efforts to eradicate poverty. World Meteorological Organization.

Jessen, M.-T., Kaarlejärvi, E., Olofsson, J., \& Eskelinen, A. (2020). Mammalian herbivory shapes intraspecific trait responses to warmer climate and nutrient enrichment. Global Change Biology, 26(12), 6742-6752. https://doi.org/10.1111/gcb.15378

Jia, S., Wang, X., Yuan, Z., Lin, F., Ye, J., Hao, Z., \& Luskin, M. S. (2018). Global signal of top-down control of terrestrial plant communities by herbivores. Proceedings of the National Academy of Sciences USA, 115(24), 6237-6242. https://doi.org/10.1073/pnas.1707984115

Jost, L. (2006). Entropy and diversity. Oikos, 113(2), 363-375. https://doi. org/10.1111/j.2006.0030-1299.14714.x

Jost, L. (2010). The relation between evenness and diversity. Diversity, 2(2), 207-232. https://doi.org/10.3390/d2020207

Kaakinen, E. (1971). Tutkimuksia Kainuun lehtokasvillisuudesta (Master's thesis). University of Oulu, Oulu, Finland.

Kaakinen, E. (1974). Kainuun ja Kuusamon lehtokasvillisuudesta (Licenciate's thesis). University of Oulu, Oulu, Finland.

Kaarlejärvi, E., Eskelinen, A., \& Olofsson, J. (2017). Herbivores rescue diversity in warming tundra by modulating trait-dependent species losses and gains. Nature Communications, 8(1), 419. https://doi. org/10.1038/s41467-017-00554-z

Kaarlejärvi, E., Salemaa, M., Tonteri, T., Merilä, P., \& Laine, A. (2021). Temporal biodiversity change following disturbance varies along an environmental gradient. Global Ecology and Biogeography, 30(2), 476489. https://doi.org/10.1111/geb.13233

Kapfer, J., Hédl, R., Jurasinski, G., Kopecký, M., Schei, F. H., \& Grytnes, J.-A. (2017). Resurveying historical vegetation data-opportunities and challenges. Applied Vegetation Science, 20(2), 164-171. https:// doi.org/10.1111/avsc.12269

Kattge, J., Bönisch, G., Díaz, S., Lavorel, S., Prentice, I. C., Leadley, P., Tautenhahn, S., Werner, G. D. A., Aakala, T., Abedi, M., Acosta, A. T. R., Adamidis, G. C., Adamson, K., Aiba, M., Albert, C. H., Alcántara, J. M., Alcázar C, C., Aleixo, I., Ali, H., ... Wirth, C. (2020). TRY plant trait database-enhanced coverage and open access. Global Change Biology, 26(1), 119-188. https://doi.org/10.1111/gcb.14904

Kattge, J., Díaz, S., Lavorel, S., Prentice, I. C., Leadley, P., Bönisch, G., Garnier, E., Westoby, M., Reich, P. B., Wright, I. J., Cornelissen, J. H. C., Violle, C., Harrison, S. P., Van Bodegom, P. M., Reichstein, M., Enquist, B. J., Soudzilovskaia, N. A., Ackerly, D. D., Anand, M.,... Wirth, C. (2011)
TRY -a global database of plant traits. Global Change Biology, 17(9), 2905-2935. https://doi.org/10.1111/j.1365-2486.2011.02451.x

Kleyer, M., Bekker, R. M., Knevel, I. C., Bakker, J. P., Thompson, K., Sonnenschein, M., Poschlod, P., van Groenendael, J. M., Klimeš, L., Klimešová, J., Klotz, S., Rusch, G. M., Hermy, M., Adriaens, D., Boedeltje, G., Bossuyt, B., Dannemann, A., Endels, P., Götzenberger L., ... Peco, B. (2008). The LEDA Traitbase: A database of life-history traits of the Northwest European flora. The Journal of Ecology, 96(6), 1266-1274. https://doi.org/10.1111/j.1365-2745.2008.01430.x

Kouki, J., Junninen, K., Mäkela, K., Hokkonen, M., Aakala, T., Hallikainen, V., Korhonen, K., Kuuluvainen, T., Loiskekoski, M., Mattila, O., Matveinen, K., Punttila, P., Ruokanen, I., Valkonen, S., \& Virkkala, R. (2018). 5.5: Metsät. In T. Kontula, \& A. Raunio (Eds.), Suomen luontotyyppien uhanalaisuus 2018 : Luontotyyppien punainen kirja. Osa 1: Tulokset ja arvioinnin perusteet (pp. 171-202). Ympäristöministeriö.

Lake, P. S., Palmer, M. A., Biro, P., Cole, J., Covich, A. P., Dahm, C., Gibert, J., Goedkoop, W., Martens, K., \& Verhoeven, J. (2000). Global change and the biodiversity of freshwater ecosystems: Impacts on linkages between above-sediment and sediment biota. BioScience, 50(12), 1099-1107.

Lavorel, S., \& Garnier, E. (2002). Predicting changes in community composition and ecosystem functioning from plant traits: Revisiting the Holy Grail. Functional Ecology, 16(5), 545-556. https://doi. org/10.1046/j.1365-2435.2002.00664.x

Maliniemi, T., Happonen, K., \& Virtanen, R. (2019). Site fertility drives temporal turnover of vegetation at high latitudes. Ecology and Evolution, 9(23), 13255-13266. https://doi.org/10.1002/ece3.5778

McElreath, R. (2020). rethinking: Statistical rethinking book package. https://github.com/rmcelreath/rethinking.

Muurinen, L., Oksanen, J., Vanha-Majamaa, I., \& Virtanen, R. (2019). Legacy effects of logging on boreal forest understorey vegetation communities in decadal time scales in northern Finland. Forest Ecology and Management, 436, 11-20. https://doi.org/10.1016/j. foreco.2018.12.048

Natural Resources Institute Finland (2020). Suomen Virallinen Tllasto (SVT): Metsästys, Riistasaalis (kpl). Natural Resources Institute Finland. https://statdb.luke.fi/PXWeb/pxweb/fi/LUKE/LUKE_06\%20Kal a\%20ja\%20riista__02\%20Rakenne\%20ja\%20tuotanto__16\%20Met sastys/5_Mets_saalis.px/?rxid=cf553b1b-570e-4211-bd97-f8906 bc8278f

Nygrén, T. (2009). Suomen hirvikannan säätely: biologiaa ja luonnonvarapolitiikkaa (PhD thesis). University of Joensuu, Finland. http://epubl ications.uef.fi/pub/urn_isbn_978-952-219-314-8/urn_isbn_978952-219-314-8.pdf

Oksanen, J. (1996). Is the humped relationship between species richness and biomass an artefact due to plot size? The Journal of Ecology, 84(2), 293-295. https://doi.org/10.2307/2261364

Oksanen, J., Blanchet, F. G., Friendly, M., Kindt, R., Legendre, P., McGlinn, D., Minchin, P. R., O'Hara, R. B., Simpson, G. L., Solymos, P., Stevens, M. H. H., Szoecs, E, \& Wagner, H. (2019). vegan: Community ecology package (version 2.5-6). R package. https://CRAN.R-project.org/ package $=$ vegan

Olofsson, J., Moen, J., \& Östlund, L. (2010). Effects of reindeer on boreal forest floor vegetation: Does grazing cause vegetation state transitions? Basic and Applied Ecology, 11(6), 550-557. https://doi. org/10.1016/j.baae.2010.03.004

Pausas, J. G., \& Bond, W. J. (2018). Humboldt and the reinvention of nature. The Journal of Ecology, 107(3), 1031-1037. https://doi. org/10.1111/1365-2745.13109

Pereira, H. M., Ferrier, S., Walters, M., Geller, G. N., Jongman, R. H. G., Scholes, R. J., Bruford, M. W., Brummitt, N., Butchart, S. H. M., Cardoso, A. C., Coops, N. C., Dulloo, E., Faith, D. P., Freyhof, J., Gregory, R. D., Heip, C., Hoft, R., Hurtt, G., Jetz, W., ... Wegmann, M. (2013). Essential biodiversity variables. Science, 339(6117), 277-278. https://doi.org/10.1126/science.1229931 
R Core Team (2019). R: A language and environment for statistical computing (version 3.6.2). R Foundation for Statistical Computing. https:// www.R-project.org/

Robinson, W. S. (1950). Ecological correlations and the behavior of individuals. American Sociological Review, 15(3), 351-357. https://doi. org $/ 10.2307 / 2087176$

Siemann, E., Tilman, D., \& Haarstad, J. (1996). Insect species diversity, abundance and body size relationships. Nature, 380(6576), 704-706. https://doi.org/10.1038/380704aO

Sundqvist, M. K., Moen, J., Björk, R. G., Vowles, T., Kytöviita, M., Parsons, M. A., \& Olofsson, J. (2019). Experimental evidence of the long-term effects of reindeer on Arctic vegetation greenness and species richness at a larger landscape scale. The Journal of Ecology, 107(6), 27242736. https://doi.org/10.1111/1365-2745.13201

Supp, S. R., \& Ernest, S. K. M. (2014). Species-level and community-level responses to disturbance: A cross-community analysis. Ecology, 95(7), 1717-1723. https://doi.org/10.1890/13-2250.1

Tonteri, T., Salemaa, M., Rautio, P., Hallikainen, V., Korpela, L., \& Merilä, P. (2016). Forest management regulates temporal change in the cover of boreal plant species. Forest Ecology and Management, 381, 115124. https://doi.org/10.1016/j.foreco.2016.09.015

van der Plas, F., Schröder-Georgi, T., Weigelt, A., Barry, K., Meyer, S., Alzate, A., Barnard, R. L., Buchmann, N., de Kroon, H., Ebeling, A., Eisenhauer, N., Engels, C., Fischer, M., Gleixner, G., Hildebrandt, A., Koller-France, E., Leimer, S., Milcu, A., Mommer, L., ... Wirth, C. (2020). Plant traits alone are poor predictors of ecosystem properties and long-term ecosystem functioning. Nature Ecology \& Evolution, 4, 1602-1611. https://doi.org/10.1038/s41559-020-01316-9

Vellend, M., Baeten, L., Myers-Smith, I. H., Elmendorf, S. C., Beausejour, R., Brown, C. D., De Frenne, P., Verheyen, K., \& Wipf, S. (2013). Global meta-analysis reveals no net change in local-scale plant biodiversity over time. Proceedings of the National Academy of Sciences USA, 110(48), 19456-19459. https://doi.org/10.1073/pnas.13127 79110

Verheyen, K., Bažány, M., Chećko, E., Chudomelová, M., Closset-Kopp, D., Czortek, P., Decocq, G., De Frenne, P., De Keersmaeker, L., Enríquez García, C., Fabšičová, M., Grytnes, J.-A., Hederová, L., Hédl, R., Heinken, T., Schei, F. H., Horváth, S., Jaroszewicz, B., Jermakowicz,
E., ... Baeten, L. (2018). Observer and relocation errors matter in resurveys of historical vegetation plots. Journal of Vegetation Science, 29(5), 812-823. https://doi.org/10.1111/jvs.12673

Violle, C., Navas, M.-L., Vile, D., Kazakou, E., Fortunel, C., Hummel, I., \& Garnier, E. (2007). Let the concept of trait be functional!. Oikos, 116(5), 882-892. https://doi.org/10.1111/j.0030-1299.2007.15559.x

Wood, S. N. (2011). Fast stable restricted maximum likelihood and marginal likelihood estimation of semiparametric generalized linear models. Journal of the Royal Statistical Society, 73(1), 3-36. https:// doi.org/10.1111/j.1467-9868.2010.00749.x

\section{BIOSKETCH}

The authors of this paper come from three universities, but all are interested in the temporal dimension of biodiversity. By combining expertise on vegetation surveys, trait-based methods, and statistical modelling, they attempt to provide mechanistic explanations for observed biodiversity changes.

\section{SUPPORTING INFORMATION}

Additional Supporting Information may be found online in the Supporting Information section.

How to cite this article: Happonen, K., Muurinen L., Virtanen R., Kaakinen E., Grytnes J.-A., Kaarlejärvi E., Parisot P., Wolff M., \& Maliniemi T. (2021). Trait-based responses to land use and canopy dynamics modify long-term diversity changes in forest understories. Global Ecology and Biogeography, 30, 1863-1875. https://doi.org/10.1111/geb.13351 